\title{
MARYBETH SHINN: INTRODUCTION
}

It is my honor to introduce Marybeth Shinn, recipient of the 1996 Distinguished Contribution Award. Before describing Beth and some of her many accomplishments to you, I ask you to reflect on this question: Why do we do this? That is, why do we as a society, a collectivity, an organization, and as a community single out individuals for recognition of their distinguished accomplishments? Why do we point to the few? Surely it is not simply to provide a symbolic reward to our colleagues for the long hours of thankless drudgery they willingly contribute as supporters and builders of institutions like Society for Community Research and Action (SCRA). We all engage in that work willingly with no expectation of reward other than the realization of our collective hopes and aspirations.

No, I believe we realize the need, both personal and collective, to see our best possible selves as they are embodied in a real person's accomplishments. We regard the person so honored as a model to be emulated and as an example that might shape our individual actions and strivings. At the same time, as a collectivity we honor individuals because they stand as a collective symbol, as a reference point for all of us in the continuing conversation that we have with each other in our own community about what we stand for and why.

So, Beth, this is no small burden, this recognition of your distinguished accomplishments by the SCRA. Like it or not (and I know it is a bit embarrassing for you), you will be held up as a role model and even, yes, as a symbol and touchstone for SCRA excellence.

Let us consider for a moment how Beth's work and her accomplishments help us with the dual tasks of elevating our individual aspirations and reinforcing and clarifying our community norms. Let me begin with the themes of her research accomplishments as they are revealed in an analysis of the record. It is possible to identify both historical eras in Beth's research and also overarching themes and continuities that have persisted over the years. An examination of the topics of Beth's research leaves me with the inescapable conclusion that the broad theme of home and community pervade all of her work. It is a subtle but persistent theme, and a minor key that runs through it is the struggle for a secure home and community for the many who do not yet have it.

Beth's early research was on group homes for children and youthchildren displaced from homes of their own, children dependent on the kindness of strangers. Soon after, Beth's work turned to deinstitutionalized patients who had been turned out of one inhospitable home (the mental hospital) to another, the street corner or the alley that has become a still harsher and even less welcoming home. Following this work, Beth's re- 
search turned to the meaning of community, home, and family for working mothers and their children. Beth's quest here was for work organizations that might be more responsive and more caring about the special needs for support and nurturance that working mothers and their children require.

Most recently the theme of home and community has returned in Beth's landmark research on homelessness. This most recent work won extraordinarily wide attention in publications in the American Psychologist, the American Behavioral Scientist, the Journal of Social Issues, and of course, the American Journal of Community Psychology. But with this research Beth has also, as she always does, taken what she and her colleagues have learned in their research into the policy arena. There she has served as expert witness, where she has informed national advisory panels and has kept the painful and compelling problems of homelessness in the public eye. All this is done with uncommon scientific rigor and intellectual honesty in an arena awash in ideology and political pressures.

Let me ask the question again: why do we single out the few? We often do so because of a distinctive way in which they express their character in their leadership. It is easy to recount many examples of Beth's leadership for the SCRA, her commitment to women in psychology, her work organizing the Society's activities, and of course her presidency. But these are merely surface manifestations of something deeper and much more important. Beth Shinn is one of those unusual people who leads because of who she is as a person. I have known Beth for at least 20 years, but there is something about her that makes you want to stand up a little bit straighter and be a little bit better when you are around her. I have never been able to explain to myself what exactly this personal quality is. But I remember it first affecting me even as she walked in the door as a brand new graduate student at Michigan. There was something there, kind of quiet intelligence and an unembarrassed willingness to be attracted to activities with a higher purpose. This was a bit unfashionable and even a little bit unsophisticated in her own cohort of first-year graduate students. These were students whose undergraduate work already marked them as accomplished and who revealed a hint of ill-concealed competitiveness. Even then, Beth's quiet, principled character stood out and got instant respect.

So both through the themes of her research and through her contributions to the Society, Beth has stood out. This would be more than enough reason for us to honor her. But Beth also has provided us a model of what a fine analytical and scientific mind can do with complex, ecologically embedded community problems. Beth has a mind of rare quality and a sensibility to match. When she turns her intelligence to a difficult scientific 
problem, like the cross-level modeling of ecological community problems, she provides an example that we turn to again and again in our own work. When students become interested in these complex problems, I make no attempt at coherent explanation myself (with good reason). Instead, I pull one of Beth's exemplary papers on cross-level analysis off the bookshelf and hand it to the student. I say something like, "read this three or four times and then let's talk about it." If I am lucky, the conversation that will eventually ensue will be one in which the student and I both learn something new, and where Beth has been the teacher.

So why do we do this, why do we make an award for distinguished contributions? By now the answer should be clear. We do it to reflect on our best individual and collective "possible selves" and in the hope that we all may do a little better both individually and collectively. Beth Shinn has given us that opportunity through the example of her work and her career. The Society for Community Research and Action honors itself by honoring Beth Shinn. Today Beth will talk to us about "Family Homelessness: State or Trait?"

Richard H. Price

University of Michigan 